\title{
Seasonal variations in a deep aggregation of Calanus pacificus in the Santa Barbara Basin
}

\author{
Kenric E. Osgood*, David M. Checkley Jr \\ Marine Life Research Group, Scripps Institution of Oceanography, La Jolla, California 92093-0218, USA
}

\begin{abstract}
A deep aggregation of fifth copepodid (C5) Calanus pacificus in the Santa Barbara Basin (SBB) was mapped over $1 \frac{1}{2}$ yr with zooplankton net tows, an optical plankton counter, and a moored acoustic Doppler current profiler. High concentrations of diapausing C5 C. pacificus built up in the deep waters of the SBB during the summer and into the fall. During the buildup, the deep aggregation moved up from the bottom as oxygen became depleted in the basin's deep waters. The deep aggregation apparently builds up due to the basin trapping C5s that migrate below the sill depth from water advected over the basin. C5s are retained within the basin until they swim, or are forced, above the sill depth. Possible mechanisms responsible for the dispersal of the deep aggregation are migration to the surface waters with subsequent dispersal by surface currents, advection over the basin's sill due to the buildup of oxygen-deficient water, or flushing of the basin's deep water.
\end{abstract}

KEY WORDS: Calanus pacificus - Deep aggregation - Santa Barbara Basin - Diapause

\section{INTRODUCTION}

Many calanoid copepod species have a dormant phase where the majority of the population stays at depth during months of low primary productivity in order to survive long periods of food shortage (e.g. Miller et al. 1984, Conover 1988). Calanus pacificus Brodsky is a common marine planktonic copepod which displays this pattern to varying degrees throughout its range. In the waters off southern California the basic seasonal cycle for C. pacificus is hypothesized to be as follows (Fleminger 1985): a portion of the $C$. pacificus population remains active in the surface $100 \mathrm{~m}$ of the water column throughout the year. Starting in late spring, however, some individuals arrest their development at the fifth copepodid (C5) stage, migrate to deeper waters ( 300 to $600 \mathrm{~m}$ ) and enter diapause. The diapausing C5s remain dormant through the fall, becoming active and rejoining the surface population sometime in winter. The factors controlling the triggering and termination of diapause in Calanus are not yet known (Hirche 1996).

\footnotetext{
- Present address: Prince William Sound Science Center, PO Box 705, Cordova, Alaska 99574, USA

E-mail: osgood@grizzly.pwssc.gen.ak.us
}

Deep dwelling, diapausing individuals are obviously important to the survival of species which have this resting stage, and to the entire ecosystem, because the diapausing individuals are a source for repopulation of the surface waters the following year. Basins adjacent to the continental shelf, such as the Santa Barbara Basin ( $\mathrm{SBB}$ ), may be especially important to local plankton dynamics because these basins' deep waters can contain intense aggregations of the resting stages of copepods. To understand the importance of these deep aggregations it is necessary to know their temporal and spatial extent, the degree to which the copepods are concentrated within the basins compared to the surrounding areas, and the processes controlling the aggregations' formation, maintenance, and dissipation.

High concentrations of diapausing C5 Calanus pacificus have been observed in the deep waters of the SBB (Alldredge et al. 1984, Osgood \& Checkley in press). Based on the size and concentration of the basin's deep C5 C. pacificus aggregation compared to the concentrations outside the basin, Osgood \& Checkley (in press) inferred the aggregation to be important to the regional C. pacificus population. This was based only on measurements made during fall and on the hypothesis that the basin aggregation is 
not static but, rather, at some time, the individuals leave the deep waters of the basin and are advected throughout the region. They also hypothesized that concentrations of diapausing C5s could build up within the basin, relative to the concentrations outside the basin, during the time when some of the $C$. pacificus population is in diapause (i.e. summer-fall) by being trapped and then retained within the SBB due to its bathymetry. To test these hypotheses, we now describe the temporal changes in the basin $\mathrm{C} 5 \mathrm{C}$. pacificus population through the year and compare these to the changes that occurred in the population outside the basin.

\section{METHODS}

The SBB is located of the coast of southern California, USA (Fig. 1). Its maximal depth is just over $600 \mathrm{~m}$ while its western sill, extending down to $472 \mathrm{~m}$ in a narrow region, is its deepest opening to the surrounding waters. We employed 3 types of sampling to describe the temporal variability of the deep C5 Calanus pacificus aggregation, a MOCNESS (Multiple Opening and Closing Net and Environmental Sensing System, Wiebe et al. 1976), an OPC (optical plankton counter, Herman 1988, 1992), and an ADCP (acoustic Doppler current profiler).

The vertical distributions of the copepodid stages of Calanus pacificus were quantified with vertically stratified zooplankton samples obtained with a MOCNESS on 4 cruises (Table 1). Details of the MOCNESS sampling and sample analysis are provided in Osgood \& Checkley (in press). Briefly, a double, $1 \mathrm{~m}^{2} \mathrm{MOC}$ NESS, equipped with 20 nets of $333 \mu \mathrm{m}$ mesh, was

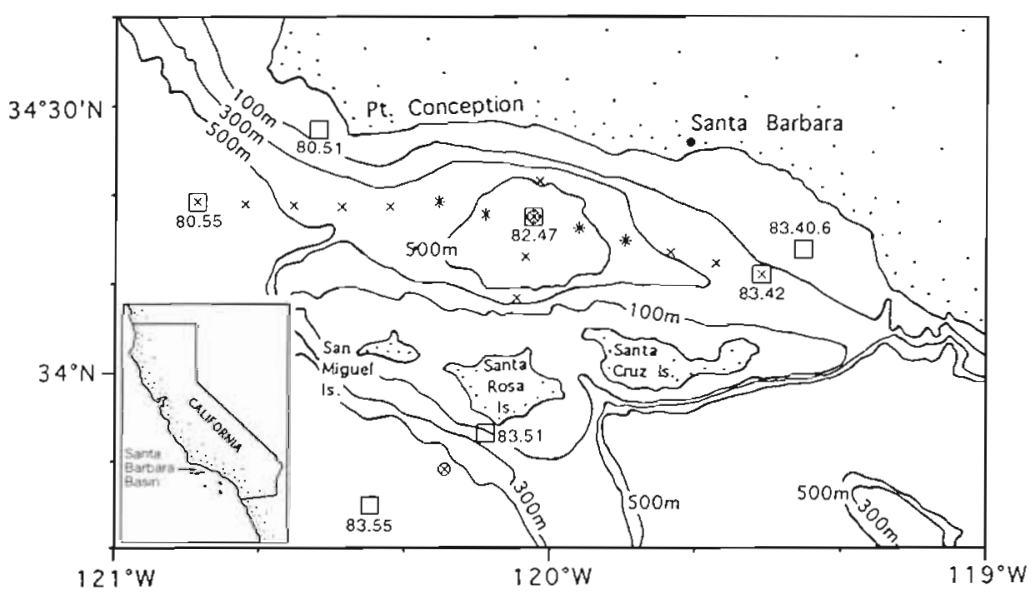

Fig. 1 Santa Barbara Basin and station locations. (o) MOCNESS stations, (x) OPC/CTD stations occupied during MOCNESS cruises, ( $\square$ ) CalCOFI stations, (+) OPC/CTD stations occupied during CalCOFI cruises (* shows superimposed $x$ and +1
Table 1. Dates and types of sampling conducted in this study. For CalCOFI, standard CalCOFl sampling was conducted in the SBB area (see Fig. 1)

\begin{tabular}{|ll}
\hline Dates & Sampling conducted \\
\hline 1994 & \\
$15-16$ Aug & CalCOFI \\
$20-21$ Aug & 5 station transect of OPC/CTD stations \\
$10-11$ Oct & CalCOFI \\
14 Oct & 5 station transect of OPC/CTD stations \\
$20-22$ Nov & MOCNESS and extensive OPC/CTD mapping \\
1995 & \\
$16-17$ Jan & CalCOFI \\
21 Jan & 5 station transect of OPC/CTD stations \\
$25-27$ Feb & MOCNESS and extensive OPC/CTD mapping \\
$16-17$ Apr & CalCOFI \\
21-23 Jun & MOCNESS and extensive OPC/CTD mapping \\
$17-18$ Jul & CalCOFI \\
22 Jul & 5 station transect of OPC/CTD stations \\
$7-9$ Sep & MOCNESS and extensive OPC/CTD mapping \\
\hline
\end{tabular}

used to obtain 10 pairs of zooplankton samples per tow, 8 of which were obtained during the retrieval of the net (near bottom to 515,515 to 475,475 to 450,450 to 400 , 400 to 200,200 to 100,100 to 50,50 to $0 \mathrm{~m}$ ). A $333 \mu \mathrm{m}$ mesh net quantitatively retains $\mathrm{C} 3$ and larger $C$. pacificus. During the November, February, and June cruises, daytime and nighttime MOCNESS tows were made at a central station within the SBB and a single tow was conducted at a station southwest of Santa Rosa Island (Fig. 1). In September, however, the only samples obtained were from a tow taken at a station within the basin. In addition to counting the copepodid stages of $C$. pacificus in the samples, we also measured the wet displacement volume of some of the samples, using the procedure outlined by Kramer et al. (1972).

Between August 1994 and September 1995 the OPC was used to map the spatial extent of the C5 Calanus pacificus deep aggregation during 8 cruises (Table 1). At each station occupied, the OPC was lowered vertically from the surface to near the bottom at a rate of $1 \mathrm{~m} \mathrm{~s}^{-1}$, providing data at $0.5 \mathrm{~s}$, hence $0.5 \mathrm{~m}$, intervals. During the November cruise, triplicate $O P C$ profiles were made at each station. During the other cruises, only single OPC profiles were conducted except at MOCNESS stations, where triplicate profiles were made. A Sea-Bird CTD (conductivity, temperature, depth) was deployed along with the OPC on each cast. During the 4 cruises when MOCNESS samples were collected, we obtained along- and cross-basin transects of OPC stations, as well as having 
an OPC station at the MOCNESS tow location southwest of Santa Rosa Island (Fig. 1). An oxygen sensor was connected to the CTD during these 4 cruises. During the September cruise, the along-basin transect did not extend as far west, but more extensive mapping was done inside the basin (see Osgood \& Checkley in press for details).

The cruises without MOCNESS tows were California Cooperative Oceanic Fisheries Investigations (CalCOFI) cruises. During CalCOFI cruises a host of oceanographic measurements are made at a regular series of stations, including 7 stations in the Santa Barbara Channel region (Fig. 1). In this paper we present oxygen concentration data from CalCOFI Stn 82.47. CalCOFI investigators determine dissolved oxygen from water samples by the Winkler method, as modified by Carpenter (1965), using the equipment and procedure outlined by Anderson (1971). We also analyzed CalCOFI bongo net samples, from the stations shown in Fig. 1, for concentrations of Calanus pacificus. The bongo nets used by the CalCOFI program are $71 \mathrm{~cm}$ diameter, $505 \mu \mathrm{m}$ mesh nets which are towed obliquely from 0 to 210 to $0 \mathrm{~m}$, bottom permitting. A $505 \mu \mathrm{m}$ mesh net quantitatively retains C5 and larger C. pacificus. In addition, during the August and October 1994 and January and July 1995 CalCOFI cruises we were able to obtain an along-basin (W-E) transect of 5 OPC/CTD stations (Fig. 1).

The OPC counts and sizes particles ranging from $250 \mu \mathrm{m}$ to $15 \mathrm{~mm}$ equivalent spherical diameter. Therefore, we needed to be able to identify which particles are C5 Calanus pacificus based upon their size and depth distribution. Details about the methods we used to approach this problem are in Osgood \& Checkley (in press); but, briefly, live C5 C. pacificus were brought into the laboratory and passed through an OPC to obtain their size-frequency distributions as sensed by an OPC. The mean $\pm 1 \mathrm{SD}$ from this distribution was taken to represent C5 C. pacificus-sized particles. In comparisons between estimates of C5 C. pacificus concentrations from MOCNESS tows and OPC profiles, the OPC was found to effectively represent C5 abundance patterns, though it generally overestimated $\mathrm{C} 5$ concentrations, except in the deep aggregation within the SBB, where it seriously underestimated their concentrations. The OPC was able to clearly delineate the deep C5 layer and was thus useful for mapping its spatial extent.

To monitor the deep currents within the SBB, and to attempt to qualitatively follow the appearance/disappearance of the deep C5 Calanus pacificus aggregation between cruises, a broadband, $150 \mathrm{kHz}$ ADCP was used. It was moored near the bottom at the central station in the SBB, oriented upwards, from 25 February 1995 to 12 January 1996. During this time period it obtained vertical profiles of the current velocities and

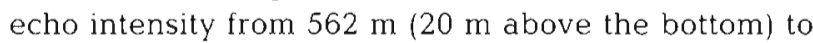
$310 \mathrm{~m}$, with a depth bin size of $4 \mathrm{~m}$. The data collected were averages from 20 pings spaced evenly through each hour. The range-corrected, relative backscatter intensity (Flagg \& Smith 1989) was calculated from the echo intensity data by first subtracting the noise level from the signal counts for each of the ADCP's 4 beams. The noise level for each beam was taken to be the echo intensity for that beam from depths far away from the transducer when the echo intensity was at low and constant values and the correlation magnitude had decreased. The average corrected echo intensity data for the 4 beams was then calculated and converted to relative backscatter intensity $(\mathrm{dB})$ using the conversion factor supplied by RD Instruments (San Diego, CA, USA). Finally, the range correction described by Flagg \& Smith (1989) was applied. This procedure generally follows that outlined by Heywood et al. (1991). There were times when some of the data above $400 \mathrm{~m}$ were meaningless due to decreases in the correlation magnitudes. Therefore, we only present data extending up to $400 \mathrm{~m}$.

For display purposes, we filtered the range-corrected backscatter data with a $38 \mathrm{~h}$, low-pass filter (pl64 filter, Limeburner 1985) for plots of several months' duration. Data for shorter time periods were also plotted without filtering to demonstrate the higher frequency fluctuations that occurred.

Sound with a frequency of $150 \mathrm{kHz}$ reflects more efficiently off particles larger than $10 \mathrm{~mm}$ than it does off smaller particles, given similar compositions. Therefore, individual C5 Calanus pacificus with a prosome length of $\sim 2 \mathrm{~mm}$ will not reflect the sound from our ADCP very efficiently, and only if they are in high concentrations will they appear as a strong backscatter signal.

\section{RESULTS}

A layer with high C5 Calanus pacificus concentration in the deep waters of the SBB was indicated by the OPC transects from August, October, and November 1994 (Fig. 2). The layer was closer to the bottom at the central OPC station in August than in October and November. MOCNESS samples obtained from the central station during November confirmed that the deep layer sensed by the OPC was composed of C5 C. pacificus, with a maximal concentration close to $7000 \mathrm{C} 5 \mathrm{~m}^{-3}$ (Fig. 3). In fact, C5s accounted for 95 to $97 \%$ of all zooplankton collected between 507 and $475 \mathrm{~m}$ during the day and between 521 to $478 \mathrm{~m}$ at night. The C5s in the deep layer showed no evidence of diel vertical migration. In the November OPC cross- 

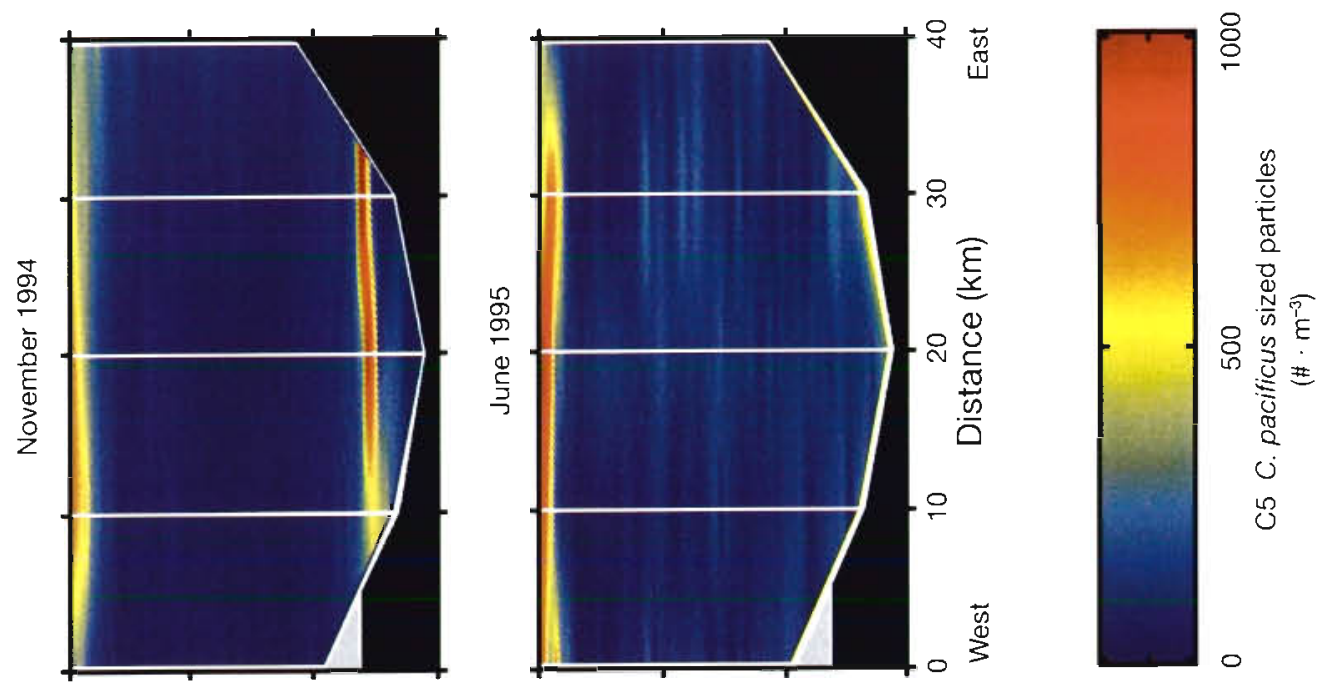

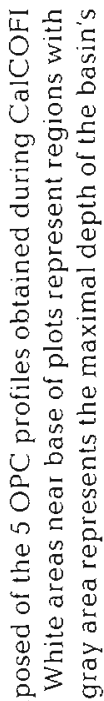
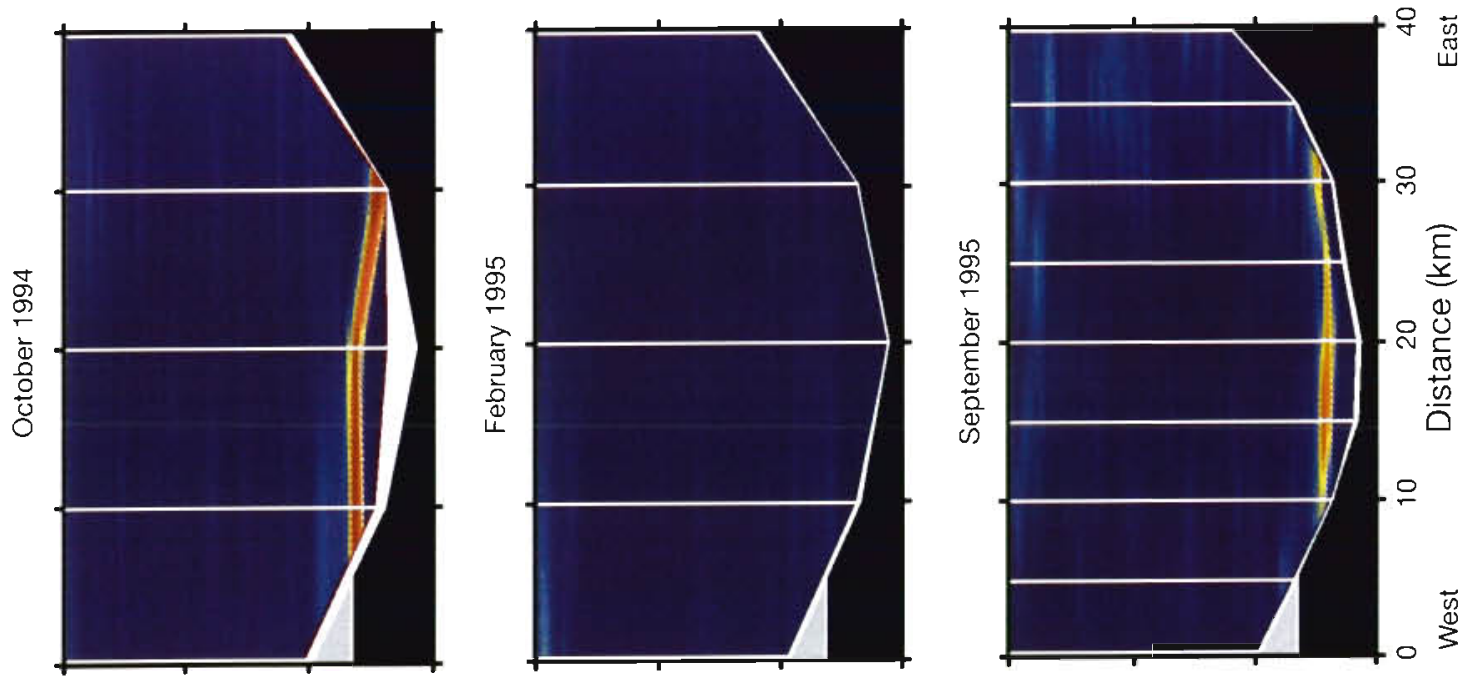

है

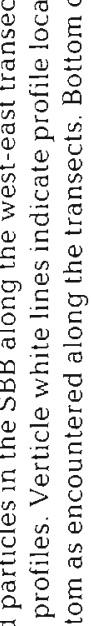

马U⿺

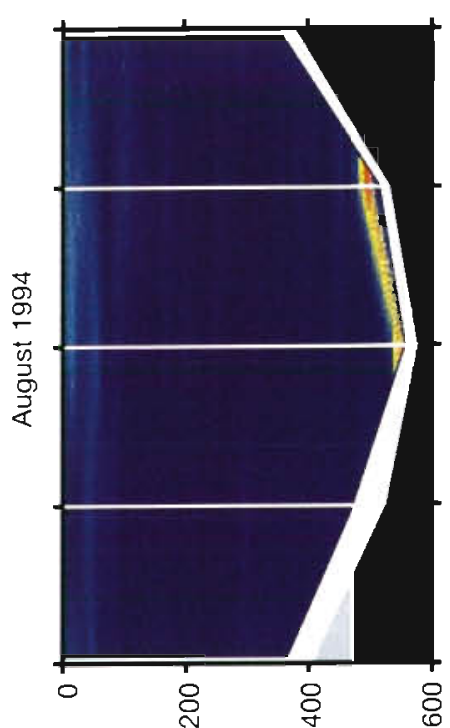

(w) ułdaO

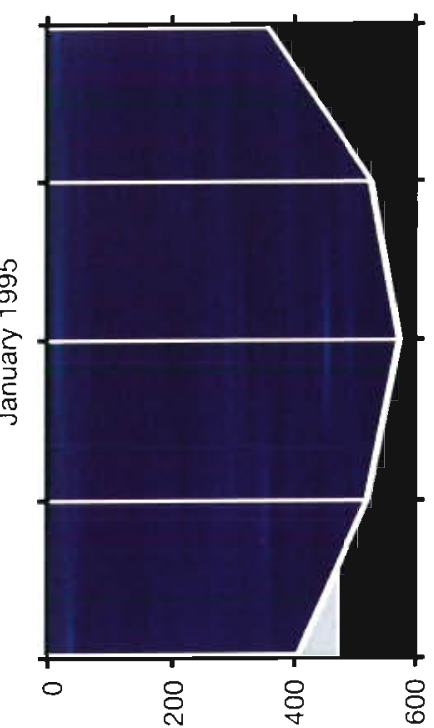

(w) $47 d \partial 0$

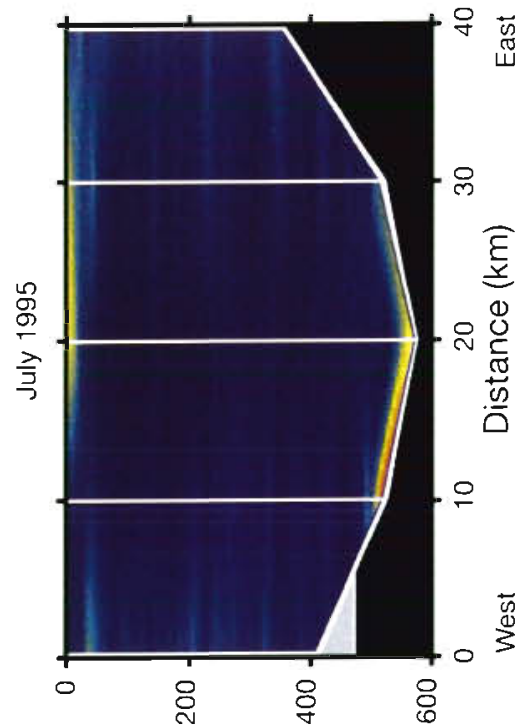

(w) 4łdəa

की 0

نे

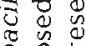

i

ㄷํㅇㄴ

U 苛

(1)

등

둥

苛吾

约

ठ

疍

揢

记资

00

त $\frac{0}{0}$

宁写 

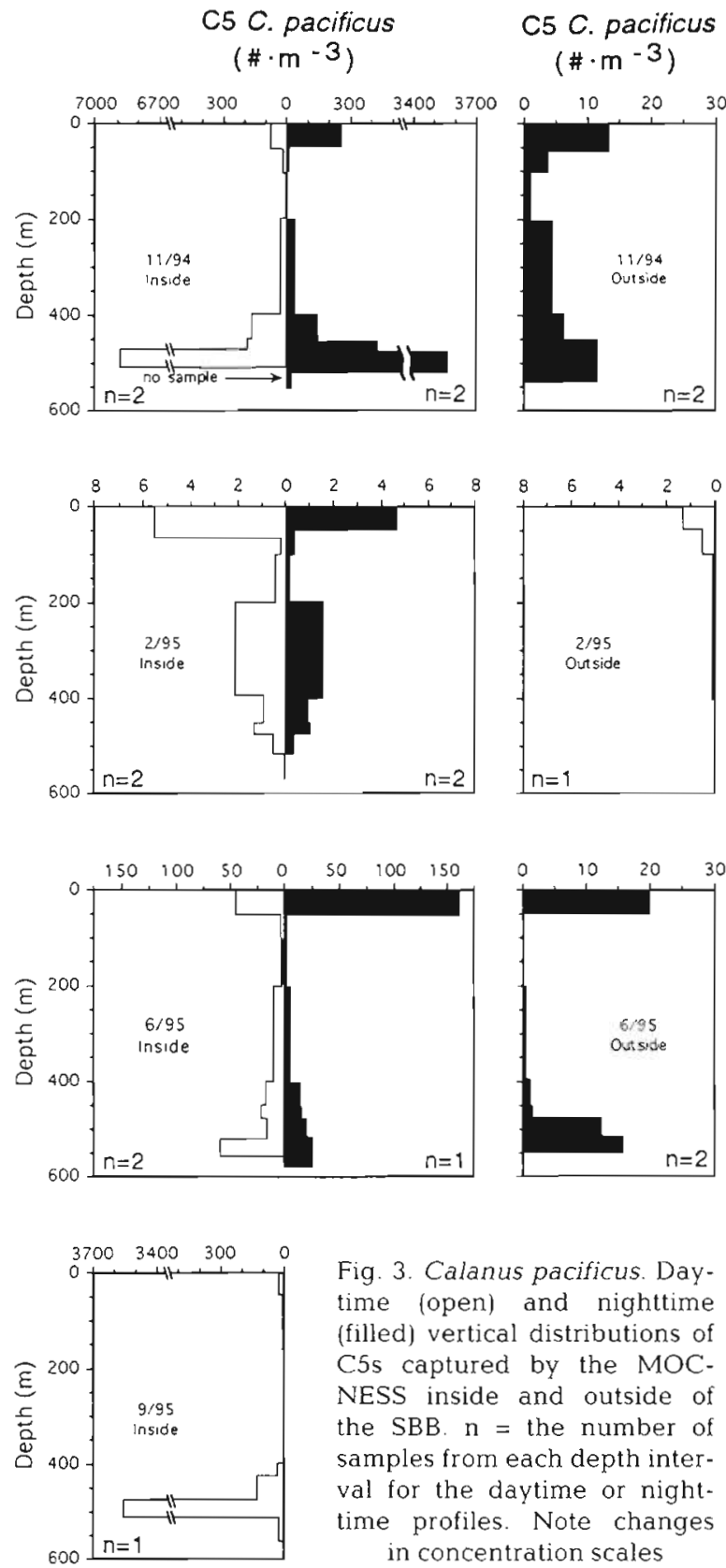

Fig. 3. Calanus pacificus. Daytime lopen) and nighttime (filled) vertical distributions of C5s captured by the MOCNESS inside and outside of the SBB. $\mathrm{n}=$ the number of samples from each depth interval for the daytime or nighttime profiles. Note changes in concentration scales water column abundance of C5s at the central station dropped dramatically between November 1994 and February 1995, yet there was only a small increase in the adult abundance (Table 2). In addition, although there were some moderate increases in the surface water concentrations of C5s and/or adults between the fall of 1994 and early 1995 at some of the stations in the SBB region (Fig. 4), large numbers of $C$. pacificus did not appear near the surface at any station.

In June 1995 the OPC indicated elevated concentrations of C5 Calanus pacificus in the surface waters and near the bottom at the 20 and $30 \mathrm{~km}$ stations (Fig 2). The June MOCNESS samples revealed that the C5s were, in fact, bimodally distributed, with concentrations similar to those present in the surface waters the previous November (Fig. 3). The aggregation in the deep layer grew and moved away from the bottom throughout the summer so that by September 1995 the distribution appeared similar to that recorded the prior fáll (Figs. 2 \& 3).

There were also seasonal changes in the oxygen concentrations in the deep waters of the SBB (Fig. 5). During the summer and fall of 1994 a bottom layer of oxygen-deficient water built up within the SBB (note the shoaling of the shoulder in the profiles). In January and February of 1995 the deep waters were still depleted of oxygen, though the upper range of this layer had not continued to shoal. In April the bottom waters contained elevated concentrations of oxygen while the water near $500 \mathrm{~m}$ was still very depleted of oxygen, indicating the basin's deep waters were being flushed at this time. Homogenization of oxygen concentrations in the waters below $500 \mathrm{~m}$ occurred by June and concentrations in June and July were higher than those recorded for the previous late summer through winter. By September 1995, though, the deepest basin waters were once again very depleted of oxygen.

At the MOCNESS station southwest of Santa Rosa Island the C5 Calanus pacificus population went through a cycle similar to that observed in the SBB,

Table 2. Calanus pacificus. Total water column abundance (no. ind. $\mathrm{m}^{-2}$ ) from MOCNESS tows at the SBB central station. Values are means of all the profiles from the central station for each cruise (November and February $n=4$, June $n=3$, September $n=1$ ) waters during November was actually C5s.

In January and February 1995 there was no indication of the deep C5 Calanus pacificus aggregation (Fig. 2). Maximal concentrations of C5s obtained with MOCNESS tows in February were found in the surface $50 \mathrm{~m}$ and were merely $5 \mathrm{C} 5 \mathrm{~m}^{-3}$ (Fig. 3). The drastic reduction in the numbers of $C 5 C$. pacificus within the SBB between the fall of 1994 and early 1995 was not due to simple maturation to adulthood. The total

\begin{tabular}{|lrrrr|}
\hline \multirow{2}{*}{ Stage } & Nov 1994 & Feb 1995 & Jun 1995 & Sep 1995 \\
\hline M & 409 & 800 & 350 & 221 \\
F & 442 & 1064 & 731 & 129 \\
C5 & 221317 & 792 & 10497 & 135287 \\
C4 & 1984 & 154 & 3823 & 452 \\
C3 & 3458 & 92 & 2860 & 704 \\
\hline
\end{tabular}




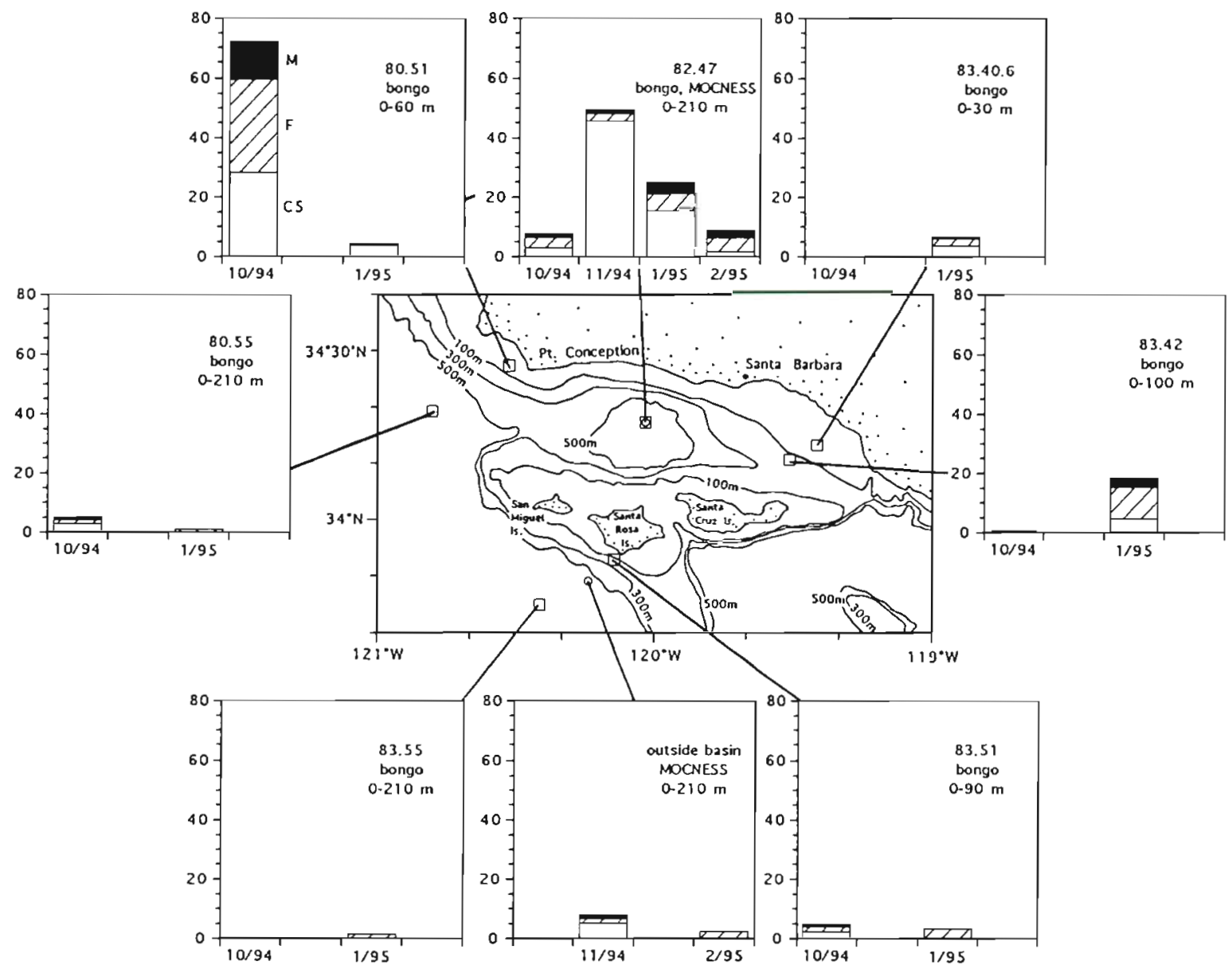

Fig. 4. Calanus pacificus. Concentrations (no. ind $\mathrm{m}^{-3}$ ) of $\mathrm{C} 5 \mathrm{~s}$ (open), adult females (striped), and adult males (filled) in the surface $210 \mathrm{~m}$ (or the entire water column if shallower than $210 \mathrm{~m}$ ). Data from $10 / 94$ and $1 / 95$ are from single CalCOFI bongo net tows. Data from 11/94 and 2/95 are means from MOCNESS tows

though during the fall the deep dwelling C5s did not accumulate in concentrations nearly as high as those in the SBB (Fig. 3). In November 1994, C5s were bimodally distributed outside the SBB, with approximately equal concentrations present in the shallow and deep waters. By February 1995, C5 C. pacificus were rare at this station and the few $\mathrm{C} 5 \mathrm{~s}$ present were located in the top $100 \mathrm{~m}$. Then by June 1995, the C5s had increased to concentrations similar to those pre- sent the previous November, and there were once again approximately equal concentrations present in the shallow and deep waters. We were not able to obtain a MOCNESS tow at this station during September 1995; however, the OPC profile from this station at this time appeared very similar to the OPC profiles obtained during the previous November and June. At this station, oxygen concentrations were fairly low in the deep waters, but never below $0.2 \mathrm{ml}^{-1}$.
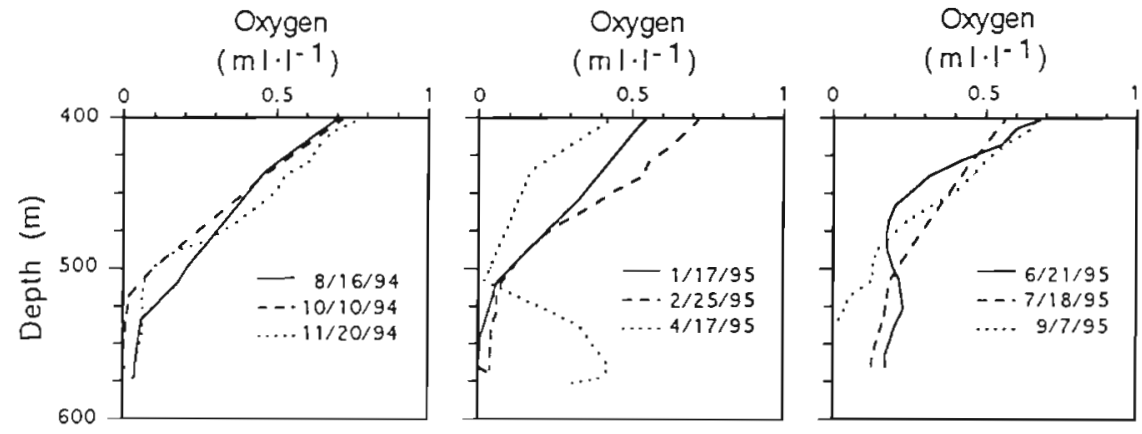

Fig. 5. Oxygen profiles below $400 \mathrm{~m}$ from the SBB central station. Sampling dates shown as $\mathrm{mo} / \mathrm{d} / \mathrm{yr}$. Profiles obtained with an in situ oxygen sensor on $11 / 20 / 94,2 / 25 / 95,6 / 21 / 95$, and 9/7/95, other profiles obtained from titration of water samples 
Since the ADCP backscatter signal is a log value, the differences between the backscatter at different depths (Fig. 6) should appear similar to the differences between the wet displacement volumes at different depths, when the volumes are plotted on a log scale (Fig. 7). When collection of ADCP data began in February 1995, the water below about $500 \mathrm{~m}$ had very low oxygen concentrations, as discussed above. The ADCP measured low levels of backscatter from this stratum (Fig. 6), indicating there were few zooplankton in the oxygen-deficient water. Above this low oxygen water, moderate and fairly constant levels of backscatter were sensed up to $400 \mathrm{~m}$. This is in good agreement with the wet displacement volumes from our MOCNESS samples at this time (Fig. 7). The intrusions of moderate backscatter levels below $500 \mathrm{~m}$ at the end of March indicate the commencement of flushing of the basin's deep waters. The flushing continued through April so that by early May moderate backscatter levels were present throughout the waters below $400 \mathrm{~m}$.

During May through early August the ADCP indicated generally higher backscatter levels from the upper portion of the profiles and the backscatter intensities generally increased during this time (Fig, 6). It is unclear from our zooplankton samples from June (Fig. 7), or OPC data from June and July, why the backscatter intensities from the upper portion of the ADCP profiles would be higher than those from the lower portion. By mid-August a continuous layer of high backscatter intensity appeared just above the bottom of the ADCP profile. A few days later, this layer shoaled a little, and just below it a layer of low backscatter appeared. This layer of high backscatter was the deep aggregation of C5 Calanus pacificus, and the area of low backscatter below it was the oxygen-deficient zone. From mid-August through September all 4 beams of the ADCP routinely indicated the presence of the deep C5 layer. The backscatter data also indicated high amounts of zooplankton in the upper portions of the ADCP profiles during much of this time, with backscatter intensities similar to those observed for the C5 layer (Fig. 6). MOCNESS samples from September indicated a low volume of zooplankton in the oxygendeficient zone and a high volume of zooplankton in the C5 C. pacificus layer (Fig. 7), in agreement with the ADCP data. However, the MOCNESS samples did not indicate volumes of zooplankton in any of the water between 400 and $475 \mathrm{~m}$ to be similar to the volumes of zooplankton present in the $\mathrm{C} 5$ layer.

Besides these long time scale fluctuations seen in the $38 \mathrm{~h}$, low-pass filtered data (i.e. flushing of the deep waters and appearance of the deep C5 Calanus pacificus layer and the oxygen-deficient zone) the ADCP backscatter data also show how the C5 layer moved up and down at a single location on a continuous basis due to the fluid motions in the SBB. In the bottom panel of Fig. 6, higher frequency fluctuations, caused by tidal and inertial motions, are apparent. The extreme events caused the $\mathrm{C} 5$ layer to move vertically $40 \mathrm{~m}$ in less than half a day!

\section{DISCUSSION}

A complete cycle of the seasonal variation in the deep C5 Calanus pacificus aggregation in the SBB was documented. The movement of the deep C5 layer away from the bottom during the summer and into the fall mirrored the movement of the upper extent of the oxygen-deficient waters within the SBB. Vinogradov et al. (1992) found Calanus euxinus (their Calanus ponticus) stopped swimming and had limited survival duration in experiments when the oxygen concentration was lowered to $0.06 \mathrm{ml} \mathrm{l}^{-1}$. If such concentrations apply to $C$. pacificus in the field, then the oxygen concentrations in the SBB's deep oxygen-deficient waters were too low for the survival of the C5s during the late summer and fall of 1994 and during September 1995. At these times the C5s were aggregated right above the oxygen-deficient waters. However, in June and July of 1995, there was sufficient oxygen in the deepest waters of the SBB for the survival of C5 C. pacificus, due to the spring flushing, and the C5s were present in highest concentrations near the bottom.

The ADCP did not sense the deep C5 layer within the SBB until mid-August because the deepest ADCP bin was $20 \mathrm{~m}$ above the bottom. Therefore, even though we noticed the formation of the deep C5 aggregation in June and July with the MOCNESS and OPC, it was mid-August before the oxygen had been sufficiently depleted in the deep waters of the SBB to force the C5s up into the range of the ADCP. Also, it is unlikely that the low-frequency ADCP would have sensed concentrations of C5s similar to those present in the deep waters during June.

Determining what caused the high backscatter from $\sim 400$ to $450 \mathrm{~m}$ for much of the ADCP mooring period is problematic. High range-corrected backscatter from more distant depth bins will occur as the limit of the ADCP range is reached. That is, the signal received by the ADCP from bins far away from the instrument is noise and remains constant, so when the signal in this region is range corrected, the farther away the bin, the higher the corrected backscatter. However, for our data below $400 \mathrm{~m}$, the echo intensity was always well above the noise level and the correlation magnitudes of all 4 beams were always high. Thus, we found no good reason to exclude data from any bins below $400 \mathrm{~m}$. Another possibility is that we made too large a range correction, making the more distant bins have 


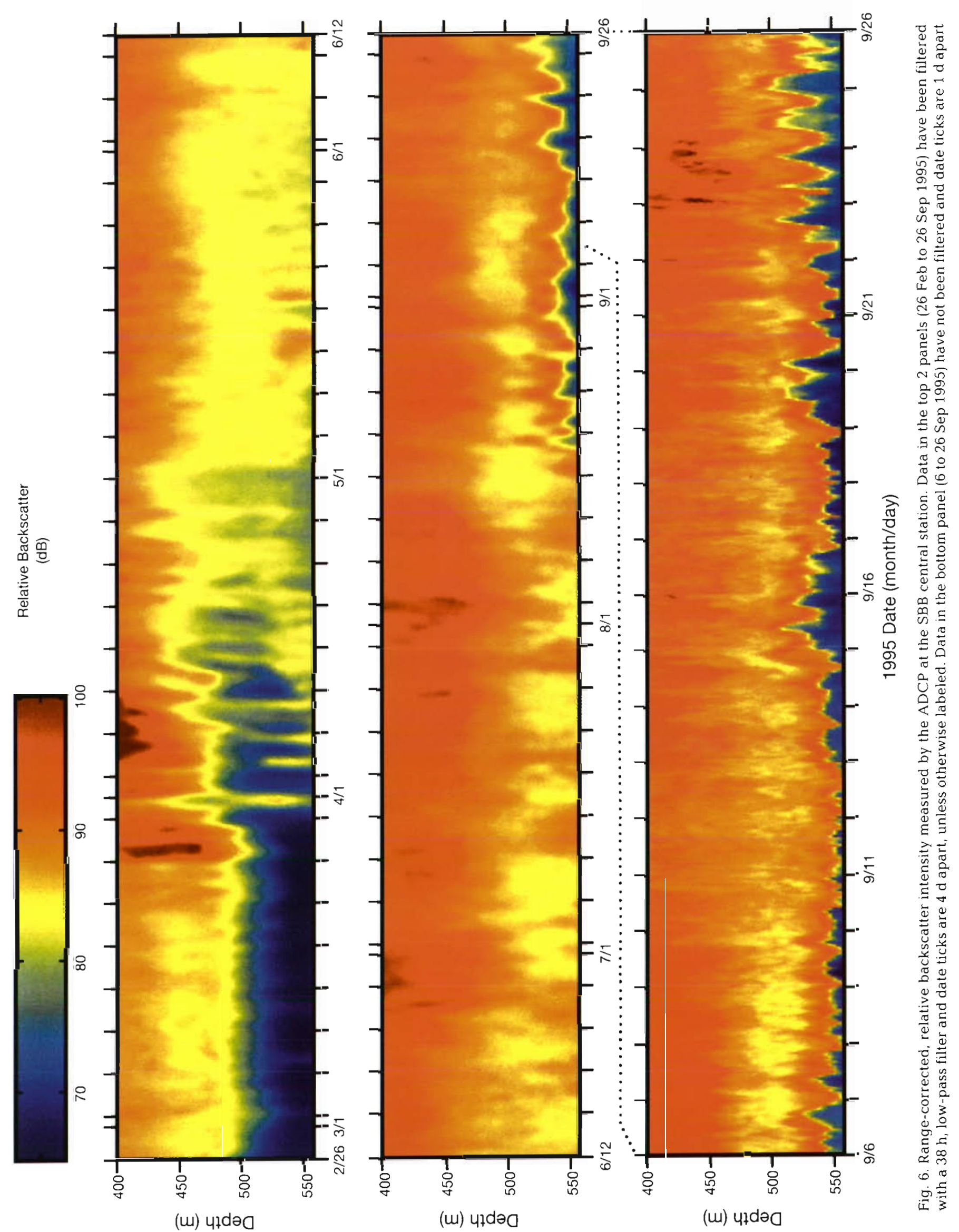


higher corrected backscatter. However, engineers at RD Instruments independently processed some of our data and obtained range-corrected backscatter values consistent with our results. This leaves the possibility that the high backscatter from $\sim 400$ to $450 \mathrm{~m}$ is real, but due to organisms not efficiently sampled by the MOCNESS or OPC. Mesopelagic fish are one such possibility. However, there was no diel variability in this backscatter as would be expected for mesopelagic fish which vertically migrate on a diel cycle.

Osgood \& Checkley (in press) remarked about the continuity of the deep C5 Calanus pacificus layer within the SBB. The ADCP backscatter data further testify to the continuity of the layer, in both time and space. The backscatter data also demonstrate the dynamics of the deep layer at a single location. Not only was the gradual shoaling of the C5 layer apparent, such as was observed with the OPC data from successive cruises, but rapid and extensive fluctuations in the depth of the layer were also observed. It is important to keep these rapid fluctuations in mind when the deep C5 layer or other properties are observed at different times. Profiles obtained with instruments such as a CTD, OPC or MOCNESS may show significant depth variation on the scale of hours.

Two questions arise, the answers to which are important to our understanding the dynamics of the Calanus pacificus populations in this region. The first question is: how does the deep C5 aggregation within the SBB build up to such high concentrations? The second question is: what happens to the individuals of the deep aggregation between fall and early winter?

\section{How does the deep aggregation build up?}

There are 2 possible mechanisms for the build up of high concentrations of diapausing C5 Calanus

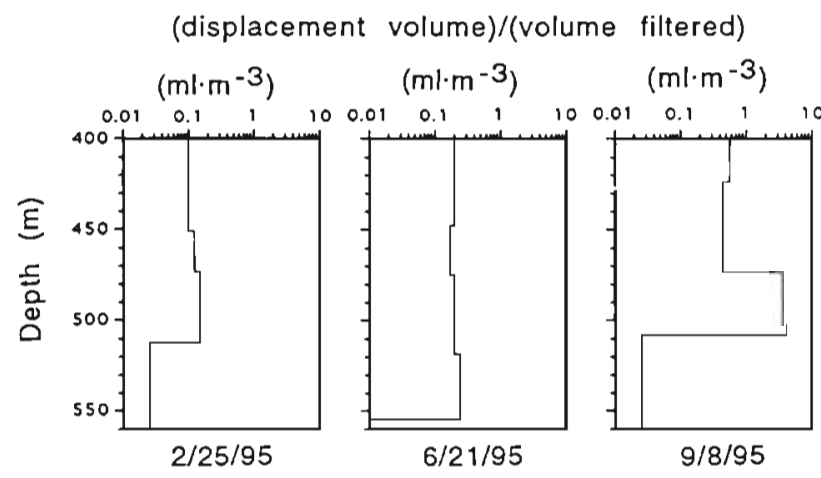

Fig. 7. Wet displacement volume/volume filtered of MOCNESS samples. Each profile is comprised of data obtained from all the daytime samples obtained for the shown depth intervals on that date. Dates shown as mo/d/yr pacificus in the SBB. These are local high reproduction in the surface waters above the SBB or, as hypothesized by Osgood \& Checkley (in press), accumulation of the $\mathrm{C} 5 \mathrm{~s}$ due to advection over the SBB of C5s that are entering diapause (or are in diapause but from shallower surrounding areas) and migrating below the basin's sill. To determine which of these mechanisms is most important, we compare the dynamics of the SBB deep aggregation to the changes in the deep dwelling $\mathrm{C} 5$ concentrations outside the basin.

At both MOCNESS stations during June, approximately equal $\mathrm{C} 5$ concentrations were observed in the surface $50 \mathrm{~m}$ and near the bottom, with slightly higher concentrations being found within the basin. By June, a portion of the Calanus pacificus population have arrested their development at the C5 stage and migrated to deeper waters for diapause while the rest of the population is still active in the surface waters. However, it has not been long since the entire population was in the surface waters (Fleminger 1985) and, hence, the deep population has not had much time to accumulate individuals from anywhere other than the presently overlying surface waters.

In contrast, during the fall, approximately equal C5 concentrations were observed in the surface and deep layers outside the SBB, but the C5 concentrations had built up substantially in the deep waters inside the basin. By fall, a portion of the Calanus pacificus population has been in diapause as deep-dwelling C5s for a long time. During this time they could have been trapped and accumulated below the basin's sill. There is no such concentrating mechanism outside the basin. The lack of below-sill-depth flushing during this period allows the $\mathrm{C} 5 \mathrm{~s}$ to be retained within the basin and also allows the oxygen-deficient waters to build up within the basin.

We conclude that the concentration differences observed between the 2 stations' deep waters during June, and surface waters at all times of year, are due to differences in local production. However, the large, deep aggregation of $\mathrm{C} 5 \mathrm{~s}$ observed in the basin during the late summer and fall is due to an accumulation of C5s from the surrounding waters. This is the same mechanism proposed for the high concentrations of deep-dwelling stages of Calanus spp. in basins on the Nova Scotia shelf (Sameoto \& Herman 1990). Advection of organisms to an area combined with a concentrating mechanism is also the explanation Wishner et al. (1995) provided for the dense Calanus finmarchicus aggregations they observed in surface waters. In their case though, the concentrating mechanism was a fluid convergence zone rather than a bathymetric retention area. 


\section{What happens to the deep aggregation?}

There are several ways the deep layer of C5 Calanus pacificus could have disappeared from the SBB. The deep waters of the SBB could have been flushed, pushing the C5s out; the C5s could have come out of diapause, migrated to the surface waters, matured to adults, and been dispersed by surface currents; the C5s could have been forced above the sill depth of the basin by the buildup of oxygen-deficient waters and then leaked out of the basin; finally, the C5s could have experienced massive mortality.

The C5s of the deep layer in the SBB were apparently not pushed out of the basin by a flushing event between November 1994 and January 1995 because the oxygen and ADCP data indicate the deep waters of the basin did not flush until April 1995. It also seems unlikely that the deep dwelling C5s experienced massive mortality between November and January: we were able to follow the layer for 3 mo prior to this with no indications of mortality events and we also followed the development of the C5 layer through the next summer and saw no indications of mortality events.

Some of the C5 Calanus pacificus in the SBB deep aggregation may have come out of diapause and migrated to the surface waters by November 1994 . The surface waters overlying the SBB did have higher concentrations of C5s in November than they did the preceding August or October (Figs. 2 \& 4). In addition, C5 concentrations in November were higher in the waters overlying the deep aggregation than they were in the surrounding waters. Even though there was no large signal in the surface waters in November or the following January that a sizable portion of the deep aggregation had migrated to the surface waters, many of the deep-dwelling C5s may have ascended after November and been dispersed from the region by the surface currents before January.

Alternatively, the deep layer of C5 Calanus pacificus in the SBB could have been forced above the western sill of the basin by the build up of oxygen-deficient waters and then advected out of the basin at depth between November 1994 and January 1995. In October and November 1994 the C5 layer's upper boundary coincided with the western sill depth (Fig. 2). Given the extent of the vertical motions that the C5 layer experiences, as manifested in the ADCP data, by fall of 1994 the C5 layer was likely above the sill depth at times and would therefore not be efficiently retained within the basin. In November the C5 layer was less concentrated closer to the western sill, consistent with some of the C5 layer having started to leak out over the sill.

We hoped to observe the disappearance of the deep layer of C5 Calanus pacificus during the fall of 1995 with the ADCP. However, after early October 1995, the C5 layer became less discrete, as it blended in with the high backscatter values above it. Due to this, it was not possible to follow the C5 layer through October and ascertain its fate. The ADCP data also indicate that a second flushing event of the deep waters of the SBB commenced in late October 1995 and continued through November. Therefore, for the disappearance of the deep C5 layer from the SBB during the fall of 1995, not only did the 2 mechanisms that seemed possible for November 1994 to January 1995 exist, but there was also the confounding effect of the flushing of the basin's deep waters. This flushing may have augmented the advective loss of C5s from the SBB over its sill.

The relative importance of the 3 dispersal mechanisms surely varies between years. Obviously, the deep waters of the basin do not flush every fall. Therefore, in some years, such as the first fall of our study, this does not contribute to the dispersal of the aggregation. The flushing of the SBB deep waters occurs mostly during the spring (Sholkovitz \& Gieskes 1971, Reimers et al. 1990). Depending upon the strength and timing of this flushing, oxygen-deficient waters can build up to varying degrees later in the year. Some years they may build up to the sill depth early enough in the fall such that most of the C5s from the deep aggregation within the basin are lost over the sill before they come out of diapause. Other years, the oxygen-depleted water may not build up sufficiently to force the C5s above the sill and the C5s may have time to come out of diapause while still in the SBB. To better determine the fate of the C5s from the deep aggregation a more detailed study centered around late fall/early winter is needed.

\section{Significance}

The diapausing C5 Calanus pacificus accumulated within the SBB are available for repopulation of the surface waters upon emerging from diapause. Osgood $\&$ Checkley (in press) found that the deep aggregation of $\mathrm{C} 5 \mathrm{C}$. pacificus in the SBB could populate approximately three $1^{\circ} \mathrm{N} \times 1^{\circ} \mathrm{W}$ blocks at the C5 abundance that was found over the entire water column outside of the basin. How aggregated the $C$. pacificus stay after leaving the deep waters of the SBB depends upon the manner in which they leave the basin, especially the length of time over which the aggregation dissipates and what the prevailing currents are during that period. The copepods from the aggregation may have a large impact in a localized region or a smaller impact over a larger region. We observed no substantial increase of adult C. pacificus in the SBB region following the disappearance of the deep aggregation. This 
may have been because our few, widely spaced net samples missed high-concentration patches or due to the coarse temporal sampling of our study combined with the length of time over which the aggregation was dispersed and the velocity of the currents into which they were dispersed. Regardless, the SBB and the conditions there are important to the regional $C$. pacificus population. Diapausing C5s trapped in the SBB are retained in waters of relatively low predator abundance (Alldredge et al. 1984) and in a region which is favorable for the growth of the copepods upon their emergence from diapause (Smith et al. 1986. Hendershott \& Winant 1996). Interannual variation in the dominant process by which the deep aggregation dissipates, i.e. vertical migration versus horizontal mixing, may cause interannual variation in the dynamics of the surface population, e.g. seeding of waters upwelled off Pt. Conception. More generally, basins in the coastal oceans may be of special importance to some zooplankton by serving as retention areas. Such basin populations may serve as seed populations for larger areas.

Acknowledgements. This research was supported by the Office of Naval Research through contract N00014-95-1-0040. We thank Michael Mullin for his comments and help on many aspects of the project and Trevor Cooper for his technical assistance. We are grateful to Thomas Hayward and the CalCOFl program for allowing us to participate on the CalCOFl cruises and providing oxygen data and zooplankton samples from these cruises. Finally, we would like to thank numerous participants on the cruises who assisted with the collection of data at sea.

\section{LITERATURE CITED}

Alldredge AL, Robison BH, Fleminger A, Torres JJ, King JM, Hamner WM (1984) Direct sampling and in situ observation of a persistent copepod aggregation in the mesopelagic zone of the Santa Barbara Basin. Mar Biol 80:75-81

Anderson GC (compiler) (1971) Marine technician's handbook, oxygen analysis. SIO Ref No. 71-8, Sea Grant Pub. No. 9. La Jolla, CA

Carpenter JH (1965) The Chesapeake Bay Institute technique for the Winkler dissolved oxygen method. Limnol Oceanogr 10:141-143

Conover RJ (1988) Comparative life histories in the genera Calanus and Neocalanus in high latitudes of the northern hemisphere. Hydrobiologia 167/168:127-142

Flagg CN, Smith SL (1989) On the use of the acoustic Doppler current profiler to measure zooplankton abundance. Deep Sea Res 36:455-474

This article was submitted to the editor
Fleminger A (1985) Dimorphism and possible sex change in copepods of the family Calanidae. Mar Biol 88:273-294

Hendershott MC, Winant CD (1996) Surface circulation in the Santa Barbara Channel. Oceanogr 9:114-121

Herman AW (1988) Simultaneous measurement of zooplankton and light attenuance with a new optical plankton counter. Cont Shelf Res 8:205-221

Herman AW (1992) Design and calibration of a new optical plankton counter capable of sizing small zooplankton. Deep Sea Res 39:395-415

Heywood KJ, Scrope-Howe S, Barton ED (1991) Estimation of zooplankton abundance from shipborne ADCP backscatter. Deep Sea Res 38:677-691

Hirche HJ (1996) Diapause in the marine copepod, Calanus finmarchichs-a review. Ophelia 44:129-143

Kramer D, Kalin MJ, Stevens EG, Thrailkill JR, Zweifel JR (1972) Collecting and processing data on fish eggs and larvae in the California Current region. NOAA Tech Rep NMFS CIRC-370, Seattle, WA.

Limeburner R (ed) (1985) CODE-2: moored array and largescale data report. WHOI Tech Rep 85-35, CODE Tech Rep No. 38. Woods Hole Oceanographic Institution, Woods Hole, MA

Miller CB, Frost BW, Batchelder HP, Clemons MJ, Conway RE (1984) Life histories of large, grazing copepods in a subarctic ocean gyre: Neocalanus plumchrus, Neocalanus cristatus, and Eucalanus bungii in the Northeast Pacific. Prog Oceanogr 13:201-243

Osgood KE, Checkley DM Jr (in press) Observations of a deep aggregation of Calanus pacificus in the Santa Barbara Basin. Limnol Oceanogr

Reimers CE, Lange CB, Tabak M, Bernhard JM (1990) Seasonal spillover and varve formation in the Santa Barbara Basin, California. Limnol Oceanogr 35:1577-1585

Sameoto DD, Herman AW (1990) Life cycle and distribution of Calanus finmarchicus in deep basins on the Nova Scotia shelf and seasonal changes in Calanus spp. Mar Ecol Prog Ser 66:225-237

Sholkovitz ER, Gieskes JM (1971) A physical-chemical study of the flushing of the Santa Barbara Basin. Limnol Oceanogr 16:479-489

Smith SL, Jones BH, Atkinson LP, Brink KH (1986) Zooplankton in the upwelling fronts off Pt. Conception, California. In: Nihoul JCJ (ed) Marine interfaces ecohydrodynamics. Elsevier Oceanography Series 42. Elsevier, Amsterdam, p $195-213$

Vinogradov ME, Arashkevich EG. Ilchenko SV (1992) The ecology of the Calanus ponitcus population in the deeper layer of its concentration in the Black Sea. J Plankton Res $14: 447-458$

Wiebe PH, Burt KH, Boyd SH, Morton AW (1976) A multiple opening/closing net and environmental sensing system for sampling zooplankton. J Mar Res 34:313-326

Wishner KF, Schoenherr JR, Beardsley R, Chen C (1995) Abundance, distribution and population structure of the copepod Calanus finmarchicus in a springtime right whale feeding area in the southwestern Gulf of Maine. Cont Shelf Res 15:475-507

Manuscript first received: September 10, 1996

Revised version accepted: November 25, 1996 